\title{
Fluctuating asymmetry as a measure of ecological stress in Drosophila melanogaster (Diptera: Drosophilidae)
}

\author{
Vincenzo TrotTa, Federico Corrado Fulceri CALBOLI, Flavio GAROIA, Daniela GRIFONi \\ and SANDRO CAVICCHI*
}

Dipartimento di Biologia Evoluzionistica Sperimentale, Università di Bologna, via Selmi 3, 40126-Bologna, Italy

Keywords. Drosophila, fluctuating asymmetry, stress, viability, developmental compartments

\begin{abstract}
Fluctuating asymmetry (FA), the small and random departures from perfect symmetry of an organism's bilateral traits, has been used as a measurement of developmental stability and an indicator of stress in endangered populations. We were interested in testing if the level of developmental stability is the same in different populations experiencing the same conditions, as the use of FA as an indicator of ecological stress is only meaningful if this is true. In order to do this, the effect of thermal stress on wing size FA over a range of temperatures was determined on three different lines of Drosophila melanogaster: two lines were maintained at one of two different constant temperatures $\left(18^{\circ} \mathrm{C}\right.$ or $\left.28^{\circ} \mathrm{C}\right)$ and one under a fluctuating thermal regime $\left(18^{\circ} \mathrm{C}\right.$ and $\left.28^{\circ} \mathrm{C}\right)$ for eight years. The differences in viability of these lines, when reared at a range of different temperatures, are associated with the temperature conditions they previously experienced. All lines showed a similar increase in FA at the two ends of the thermal range but with significantly different mean values. The two units of wing development (compartments) differed in their FA response depending on the selective history of each line. We discuss the implication of our results for the use of FA as an indicator of ecological stress .
\end{abstract}

\section{INTRODUCTION}

Developmental stability refers to an organism's ability to buffer environmental and genetic perturbations experienced during its ontogeny (Waddington, 1942; Zakharov, 1992; Clarke, 1998). It is assumed that it is influenced by genotype, environment and/or genotype by environment interactions (Van Dongen \& Lens, 2000). The small and random departures from perfect symmetry in an organism's bilateral traits are described as fluctuating asymmetry (FA).

FA appears to be taxon, trait and stress specific (David et al., 1998; Roy \& Stanton, 1999; Völlestad et al., 1999; Bjorksten et al., 2000b, 2001), indicating that environmental noise has a different impact on developing organs and organisms. It is also suggested that increased asymmetry reflects an increased inability to cope with stressful situations (Palmer \& Strobeck, 1986; Pomiankowsky, 1997). This hypothesis would imply that individual FA could be used as a measure of genetic and/or environmental stress and give useful information on individual genotypic quality. Nevertheless, the relation between developmental instability and stress is not obvious. For instance, a review by Bjorksten et al. (2000a) of experiments in which stress was manipulated found a general increase in FA in one third of the studies, a trait and stress specificity in one third and no association in the remaining third. It is reasonable to expect that, in natural situations, the relationship between FA and stress would be even less consistent and reliable (Rasmuson, 2002).

The use of FA as an indicator of developmental stability and a measure of ecological stress (Parsons, 1961, 1962, 1990, 1992; Van Valen, 1962; Palmer \& Strobeck,
1986; Leary \& Allendorf, 1989; Markow, 1995; Clarke \& McKenzie, 1997; Imasheva et al., 1997; Roy \& Stanton, 1999; Kark et al., 2001; Mpho et al., 2002; Velickovic, 2004) is based on the assumption that a stressful environment would result in higher FA levels than those observed in optimum environments. This assumption would be supported if there were a consistent level of developmental stability of traits across populations. A consistent developmental stability would give rise to a similar level of FA under the same conditions in all populations. Nevertheless, in the field a number of uncontrolled factors can confound the relationship between stress and FA. Different levels of FA would not necessarily reflect different levels of stress if developmental stability is not constant; a non constant developmental stability could also cause the same level of FA under different levels of stress.

In the present study we are interested in determining whether levels of developmental stability, measured as FA, are the same in different populations reared under the same conditions. The use of FA as an indicator of ecological stress is only meaningful if this is true.

We measured wing size FA and viability over a wide range of temperatures in different lines of Drosophila melanogaster maintained for several years at one of two fixed temperatures $\left(18^{\circ} \mathrm{C}\right.$ or $\left.28^{\circ} \mathrm{C}\right)$, or under a fluctuating thermal regime $\left(18^{\circ} \mathrm{C}\right.$ and $\left.28^{\circ} \mathrm{C}\right)$. The temperature used for the test ranged from ideal (from $18^{\circ} \mathrm{C}$ to $25^{\circ} \mathrm{C}$ ) to stressful $\left(12^{\circ} \mathrm{C}\right.$ and $\left.30^{\circ} \mathrm{C}\right)$. Viability was used as a measure of differentiation between populations and as indicator of stressful conditions. Drosophila wing size is a trait that shows a significant increase in FA in stressful environments (Parsons, 1990; Imasheva et al., 1997). In

\footnotetext{
* Corresponding author; e-mail: sandro.cavicchi@unibo.it
} 
addition, the analysis of FA of wing size in Drosophila offers the opportunity to investigate the effect of environmental stress and of different selective histories on the FA shown by different units of development within the same organ. The wing of Drosophila can be subdivided into Anterior and Posterior compartments (Garcia-Bellido et al., 1973), which are under different genetic control and thus distinct units of selection (Cavicchi et al., 1985; 1991; Guerra et al., 1997; Pezzoli et al., 1997).

\section{MATERIAL AND METHODS}

\section{The origin of the lines}

The lines used in this experiment were derived from a natural population sampled near Bologna, Italy, in October 1991. The offspring of thirty fertilized females were divided in three lines, and kept at $18^{\circ} \mathrm{C}, 28^{\circ} \mathrm{C}$ or in alternate generations at 18 and $28^{\circ} \mathrm{C}$. This procedure was repeated for a second group of thirty fertilized females, giving two replicates for each selection regime and a grand total of 6 independent lines. Each generation was reared on a standard medium in $250 \mathrm{ml}$ bottles. On emergence, thirty pairs were collected and allowed to lay eggs for two days. The larval density was approximately the same and optimal in all the cultures.

\section{Experimental procedure}

The experiment started at the end of 1999 when, on the basis of our previous experience (Cavicchi et al., 1985, 1991), the lines were likely to be adapted to each selection regime. Groups of eggs laid at $25^{\circ} \mathrm{C}$ by fertilized females of each line and replicate were collected and transferred to $60 \mathrm{ml}$ vials containing 10 $\mathrm{ml}$ of food. The vials were maintained until adult emergence at $12^{\circ} \mathrm{C}, 14^{\circ} \mathrm{C}, 18^{\circ} \mathrm{C}, 25^{\circ} \mathrm{C}, 28^{\circ} \mathrm{C}$ or $30^{\circ} \mathrm{C}$. Six vials containing 70 eggs each were collected for the two replicates of each line at $18^{\circ} \mathrm{C}, 25^{\circ} \mathrm{C}$ and $28^{\circ} \mathrm{C}$, while twelve vials were necessary at $12^{\circ} \mathrm{C}, 14^{\circ} \mathrm{C}$ and $30^{\circ} \mathrm{C}$ in order to get a sufficient number of flies. For the line adapted to $28^{\circ} \mathrm{C}$, twenty-four vials were necessary for each replicate at $12^{\circ} \mathrm{C}$. At emergence, up to thirty females of each line and replicate were collected; right and left wings were dissected and dehydrated in ethanol and mounted on slides in lactic acid/ethanol $(6: 5)$.

A digital image at a magnification of $50 \times$ of the whole wing and of the two developmental compartments (Fig. 1) was taken using a camera mounted on an optical microscope and the area measured with Image Pro Plus, by Media Cybernetics. The L4 vein was taken as the approximate boundary between the Anterior and Posterior compartments.

\section{Viability}

Viability was measured as egg-to-adult survival after pooling the results for all vials within each replicate. Pre-adult survival was transformed by taking the square root of the arcsine of the percentage value before analysis.

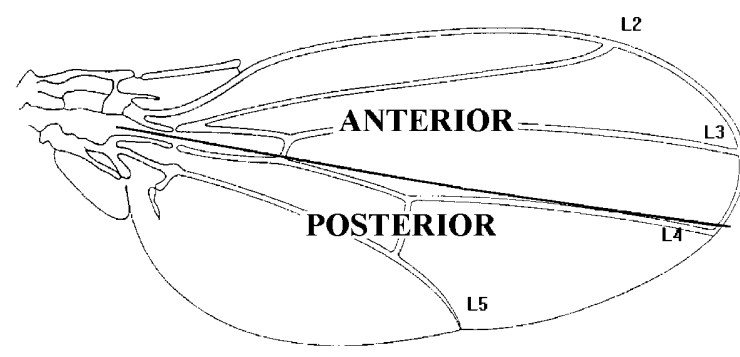

Fig. 1. Schematic representation of the adult wing of Drosophila melanogaster. L2-L5 are longitudinal veins.

\section{Tests for directional asymmetry and antisymmetry}

Distributions of signed asymmetries (L-R) of each trait were tested for normality and mean equal to zero, to detect the presence of directional asymmetry (DA) or antisymmetry (Palmer \& Strobeck, 1986; Palmer, 1994). For each trait (at each temperature, for all the lines) departure of the mean (L-R) from an expected mean of zero was tested using a one-sample $t$-test. Testing for platykurtic departures from normality of the distribution of (L-R) is the appropriate test for the presence of antisymmetry (Palmer \& Strobeck, 1986). In all cases the average FA was not significantly different from zero, when tested using one sample $t$-tests and Bonferroni correction. FA was normally distributed, based on skew and kurtosis statistics for (L-R) (Sokal \& Rohlf, 1981).

\section{Measurement error}

Relative to the size of the trait measured, fluctuating asymmetries are small and measurements must be replicated in order to distinguish true asymmetry from measurement error. When sample sizes are large, however, repeated measure of the whole sample may not be practical and the effect of the measure error should be calculated from repeated measures of a sub-sample (Palmer, 1994). In this study, the wing size of a sub sample of thirty randomly chosen individuals was measured a second time without knowledge of the first measure. A two-way ANOVA was performed on the repeated measures of these individuals with "Side" kept as fixed effect and "Individual" as random (Palmer \& Strobeck, 1986; Palmer, 1994). The interaction term of the two-way ANOVA, which contains information about FA, was tested against error mean square, reflecting measurement error. Fluctuating asymmetry "mean square" was significantly larger than measurement error "mean square" in the sub sample of thirty individuals $\left(\mathrm{F}_{(29,60)}=4,98, \mathrm{P}<0.0001\right)$.

\section{FA and trait size}

The individual FA of each trait was estimated as the absolute difference $(|\mathrm{L}-\mathrm{R}|)$ between sides of each wing region standardized over the mean trait size of each group, corresponding to the index FA19 of Breuker \& Brakefield (2003), which is a multisample variant of FA3 (Palmer \& Strobeck, 2002). This procedure was chosen to avoid the effect of size on FA due to the growth at different temperatures and previous temperature selection (Azevedo et al., 1996; James et al., 1997). This was done for both whole wing and areas of Anterior and Posterior compartments.

Since unsigned asymmetry has a half-normal distribution, the data were transformed for all traits using a two-parameter Box-Cox power transformation of the form $\left(\mathrm{Y}+\lambda_{2}\right)^{\lambda 1}$, suitable for normalizing skewed positive data containing zeroes (Palmer $\&$ Strobeck, 1986; Swaddle et al., 1994). The $\lambda$ did not significantly differ among traits and populations. The final transformation equation took the form of $\mathrm{X}=(\mathrm{Y}+0.00003)^{0.4}$.

\section{Statistical procedure}

Only four individuals were obtained in one replicate of the $28^{\circ} \mathrm{C}$ line reared at $12^{\circ} \mathrm{C}$. These individuals were not used to detect FA and this prevented the use of a standard nested ANOVA with random effects. To obviate this problem, the effects of replicates and their interaction with temperature were firstly tested for each line separately. In all cases they were not significant $(\mathrm{P}>0.05$ after Bonferroni correction). Thereafter, we used a Type III Sum of Squares ANOVA on the mean value of each replicate and temperature for each line.

The choice of this kind of analysis was also justified because our interest was limited to testing fixed effects. The Type III 


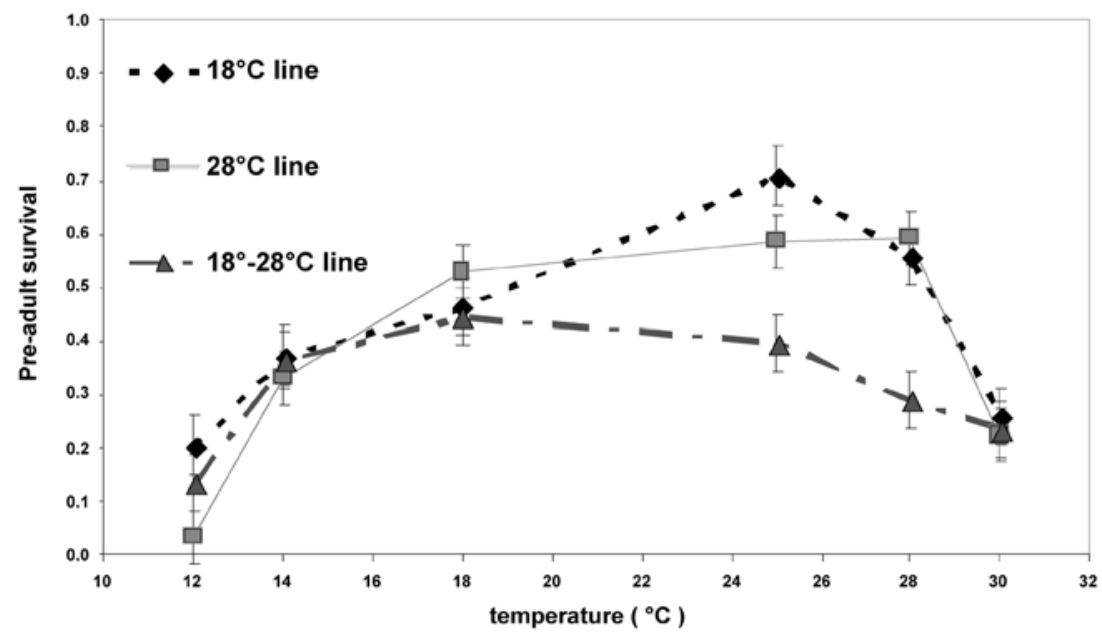

Fig. 2. Proportion of larvae surviving to the adult stage of three selected lines when reared at a range of temperatures ( \pm S.E. $)$.

Sum of Squares ANOVA was used for testing both viability and FA values. All analyses were performed with R 1.8.0 for Linux.

\section{RESULTS}

\section{Viability}

Pre-adult survival was highest at intermediate temperatures and strongly decreased at both extremes of the thermal range in all lines (Fig. 2). A two way ANOVA revealed a significant interaction between lines and temperature $\left(\mathrm{F}_{(10,18)}=3.65 ; \mathrm{p}=0.012\right)$. As mentioned above, the $28^{\circ} \mathrm{C}$ line showed a dramatically decreased pre-adult survival at $12^{\circ} \mathrm{C}$ : one of the two replicates showed a viability of about $0.2 \%$, and the second of about $3 \%$.
However, the two lines behaved in a similar way at higher temperatures. The $18^{\circ}-28^{\circ} \mathrm{C}$ line had the lowest pre-adult survival at intermediate temperatures but not at the extremes of the thermal range.

\section{Whole wing area FA}

The ANOVA on the whole wing area FA did not reveal significant interaction between lines and temperatures, while main effects were both significant (Table 1), indicating that the three selected lines evolved different FA. Temperature affected FA, with the lowest FA at intermediate temperatures and higher FA at the two extremes (Fig. 3). The highest FA was observed in the $28^{\circ} \mathrm{C}$ line, the lowest in the $18^{\circ} \mathrm{C}$ line. The $18^{\circ}-28^{\circ} \mathrm{C}$ line showed an



Fig. 3. Mean FA ( \pm S.E.) of the whole wing area in the three lines.

TABLE 1. ANOVA to test the differences in FA (Whole wing, Anterior and Posterior compartments) of flies of the three lines reared at different temperatures.

\begin{tabular}{lcccc}
\hline \multirow{2}{*}{ Traits } & \multicolumn{4}{c}{ Sources of variation $^{1}$} \\
\cline { 2 - 4 } & Temp. (5) & Lines $(2)$ & $\mathrm{L} \times \mathrm{T}(10)$ & Within (17) \\
\hline Whole wing & $0.0000818^{* *}$ & $0.0000260^{*}$ & 0.0000260 & 0.0000510 \\
Anterior compartment & $0.0001341^{* *}$ & 0.0000109 & 0.0000384 & 0.0001026 \\
Posterior compartment & $0.0001348^{* *}$ & $0.0000319^{*}$ & 0.0000307 & 0.0000571 \\
\hline
\end{tabular}

$* \mathrm{P}<0.05 ;{ }^{* *} \mathrm{P}<0.01 ;{ }^{1}$ d.f. are in parenthesis. 


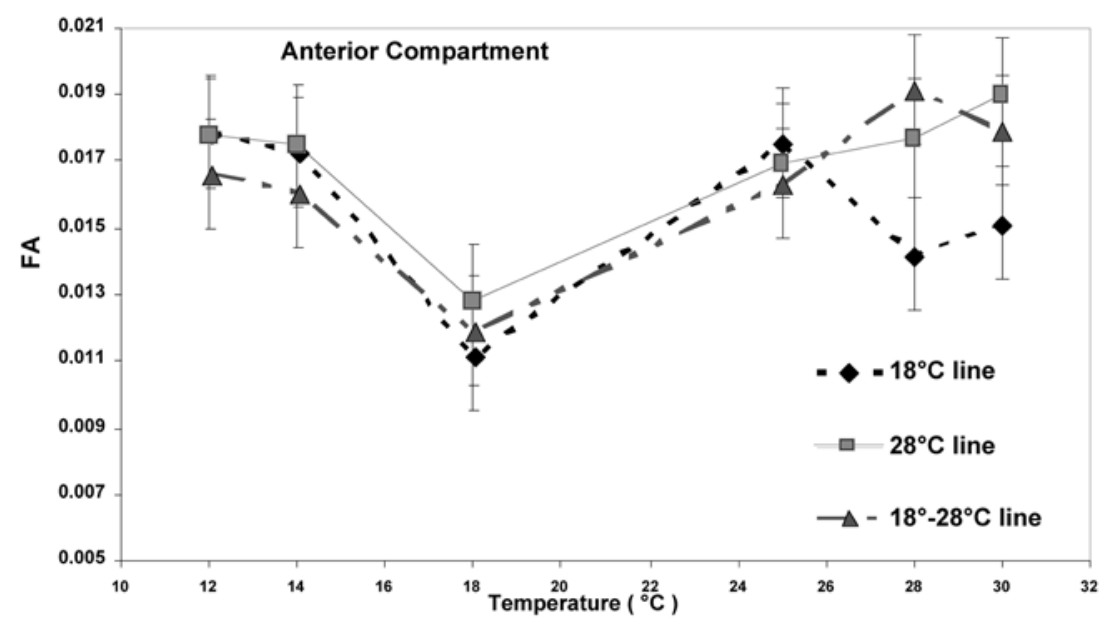

Fig. 4. FA of the Anterior wing compartment area ( \pm S.E.) of individuals of the three lines reared at different temperatures.

intermediate FA compared to the fixed temperature lines, but moving towards the FA values of the $28^{\circ} \mathrm{C}$ line at high temperatures and towards the $\mathrm{FA}$ values of the $18^{\circ} \mathrm{C}$ line at low temperatures.

\section{Wing compartments FA}

ANOVA was performed also on the FA of the two wing compartments, independently. In the Anterior compartment neither significant interaction between lines and temperature nor differences of FA were observed (Table 1). The effect of temperature was significant, with higher FA at the two extremes and lower FA at intermediate temperatures (Fig. 4).

In the Posterior compartment, no interaction was detected but the three lines differed in FA (Table 1, Fig. 5). Again, the effect of temperature was significant. As in the whole wing analysis, the $28^{\circ} \mathrm{C}$ line showed the highest $\mathrm{FA}$, the $18^{\circ} \mathrm{C}$ line the lowest $\mathrm{FA}$ and the $18^{\circ}-28^{\circ} \mathrm{C}$ line an intermediate $\mathrm{FA}$ value.

\section{Correlation between FA and viability}

Correlation between FA and viability was not significant for the Anterior compartment $\left(\mathrm{r}_{(33)}=-0.23, \mathrm{p}=\right.$
0.18), significant for the Posterior compartment $\left(\mathrm{r}_{(33)}=\right.$ $-0.36, p=0.03)$ and again not significant for the wing considered as a whole $\left(r_{(33)}=-0.3, p=0.08\right)$.

\section{DISCUSSION}

The use of wing FA was proven to be effective in measuring developmental instability in Drosophila (Hoffmann \& Parsons, 1991; Imasheva et al., 1997). In our experiment, thermal stress in Drosophila melanogaster affected both viability and FA. Viability was the lowest at the two extremes of the thermal range in all lines and showed interaction between lines and temperature (Fig. 2 ). Because all lines were originally derived from the same population, this differentiation seems to be the consequence of eight years of thermal selection the flies were subjected to prior to this study. In fact, the $28^{\circ} \mathrm{C}$ line almost completely lost the ability to survive at $12^{\circ} \mathrm{C}$ and performed relatively better than the $18^{\circ} \mathrm{C}$ line at the higher but not extreme temperatures. The $18^{\circ}-28^{\circ} \mathrm{C}$ line showed a relatively low pre-adult survival at intermediate temperatures and relatively high survival at the extremes of the thermal range. This could be evidence of trade-offs

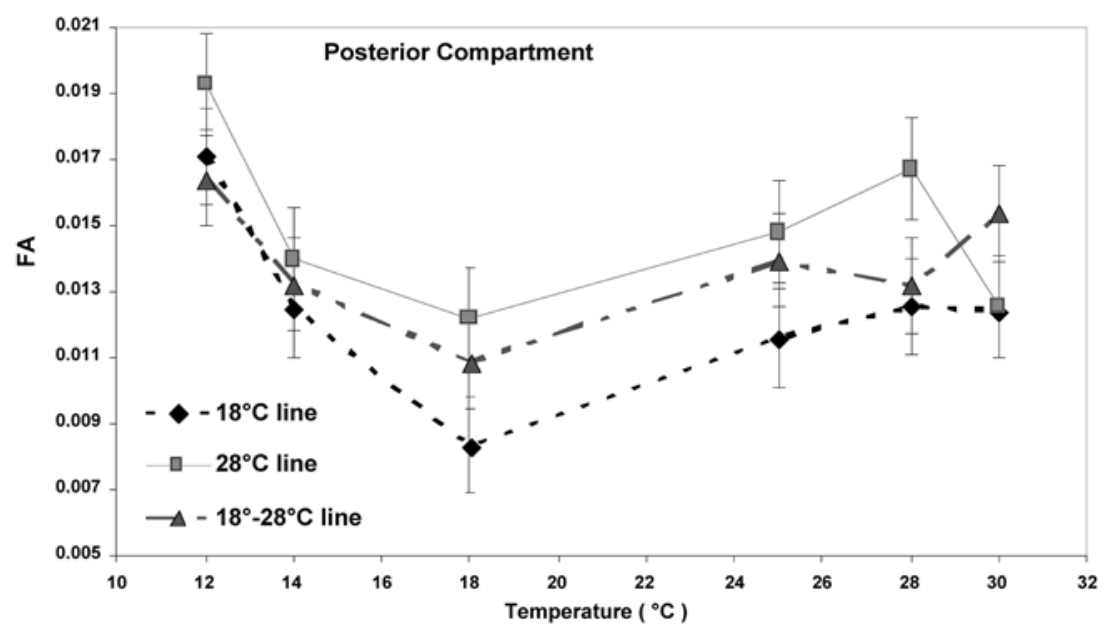

Fig. 5. FA of the Posterior wing compartment area ( \pm S.E.) of individuals of the three lines reared at different temperatures. 
caused by selection at both temperatures. The length of the temperature selection period is comparable to that used in other laboratory selection experiments (see Cavicchi et al., 1985, 1989, 1991 for body size) and other traits are also likely to have been affected.

The three lines showed a similar increase in wing area FA at the extremes of the thermal range for the whole wing as well as for the two wing compartments (Fig. 3 and Table 1); FA was higher in the $28^{\circ} \mathrm{C}$ line than in the $18^{\circ} \mathrm{C}$ line, while the $18^{\circ}-28^{\circ} \mathrm{C}$ line showed an intermediate FA, comparable to the $28^{\circ} \mathrm{C}$ line at high temperatures and the $18^{\circ} \mathrm{C}$ line at low temperatures.

As indicated by the relatively low correlation coefficient, viability and FA are not, in this case, equivalent indexes of stress, especially for comparisons among lines. One would expect low viability, indicating unfavourable environment, to be reflected in FA. A discrepancy in these two indexes would be observed if the genetic and developmental mechanisms underlying viability and FA were different, or, as suggested by Hendrickx et al. (2003) and Lens et al. (2002), individuals with higher developmental instability had reduced survival, lowering the power of FA as stress indicator; such a result is expected, as in our case, under extreme conditions.

When the two wing compartments were considered separately (Fig. 4 and 5; Table 1), significant differences between lines were found only in the Posterior compartment. Previous experiments (Cavicchi et al., 1985, 1991, Guerra et al., 1997, Pezzoli et al., 1997) suggest that wing compartments are units of genetic and developmental control of wing size and shape in both natural and laboratory populations, and that natural selection has greater effect on the Posterior compartment. Results of artificial selection for size on the various wing regions (Guerra et al., 1997) suggest that the Anterior compartment possesses the driving properties for wing development, because the genes responsible for size variation in the Posterior compartment are hypostatic to those controlling the Anterior one. In addition, regions located in the Anterior compartment appear to initiate cell proliferation before those located in the Posterior compartment. This difference could explain the lower genetic and developmental flexibility shown by the Anterior compartment. The effect of selection on the whole wing FA reflected more closely the response of the Posterior rather than the Anterior compartment. These results indicate that the different subunits of development respond differently to natural selection, which affects their FA. Our results suggest that, within the same organ, different developmental subunits can show a similar pattern of FA across a range of environmental conditions, but do not necessarily reflect the selective history of a population in the same way.

Our results also show that thermal selection in the laboratory shifted the relative level of developmental stability towards different optima. As a consequence, the level of FA has a different mean value in the three lines. The relative optimality of each level of developmental stability would explain why FA values change across the thermal range but constant differences among lines remain.

The legitimate use of FA as a measure of ecological stress requires attention to a number of points. For instance, can we compare the whole wing FA of the $18^{\circ} \mathrm{C}$ line grown at $30^{\circ} \mathrm{C}$ with the whole wing $\mathrm{FA}$ of the $28^{\circ} \mathrm{C}$ line grown at $18^{\circ} \mathrm{C}$ if a developmental temperature of $30^{\circ} \mathrm{C}$ is not stressful for the $18^{\circ} \mathrm{C}$ line? The answer is clearly no, if the response of the $18^{\circ} \mathrm{C}$ line over the whole thermal range is not taken into account. This simple observation indicates that information on the genetic make up of the test and control population is needed before drawing firm conclusions. If it is not possible to prove that the test and control populations have a similar developmental stability and response to environmental variation, the use of FA as a measure of environmental stress is dubious.

ACKNOWLEDGMENTS. We thank C.J. Breuker and C. Pertoldi for useful advice on the methodological approach and V. Loeschcke for helpful suggestions on the manuscript. This work was supported by a grant from Bologna University (Italy).

\section{REFERENCES}

Azevedo R.B.R., French V. \& Partridge L. 1996: Thermal evolution of egg size in Drosophila melanogaster. Evolution 50: 2338-2345.

Bjorksten T.A., Fowler K. \& Pomiankowski A. 2000a: What does sexual trait FA tell us about stress? Trends Ecol. Evol. 13: $163-166$.

Bjorksten T.A., David P., Pomiankowski A. \& Fowler K. 2000b: Fluctuating asymmetry of sexual and nonsexual traits in stalk-eyed flies: a poor indicator of developmental stress and genetic quality. J. Evol. Biol. 13: 89-97.

Bjorksten T., Pomiankowski A. \& Fowler K. 2001: Temperature shock during development fails to increase the fluctuating asymmetry of a sexual trait in stalk-eyed flies. Proc. $R$. Soc. London (B) 268: 1503-1510.

Breuker C.J. \& Brakefield P.M. 2003: Lack of response to selection for lower fluctuating asymmetry of mutant eyespots in the butterfly Bicyclus anynana. Heredity 91: 17-27.

Cavicchi S., Guerra D., Giorgi G. \& Pezzoli M.C. 1985: Temperature-related divergence in experimental populations of Drosophila melanogaster. I. Genetic and developmental basis of wing size and shape variation. Genetics 109: 665-689.

Cavicchi S., Guerra D., Natali V., Pezzoli M.C. \& Giorgi G. 1989: Temperature-related divergence in experimental populations of Drosophila melanogaster. II. Correlation between fitness and body dimensions. J. Evol. Biol. 2: 235-251.

Cavicchi S., Giorgi G., Natali V. \& Guerra D. 1991: Temperature-related divergence in experimental populations of Drosophila melanogaster. III. Fourier and centroid analysis of wing shape and relationship between shape variation and fitness. J. Evol. Biol. 4: 141-159.

Clarke G.M. \& McKenzie J.A. 1997: Developmental stability of insecticide resistant phenotypes in blowfly; a result of canalizing natural selection. Nature 325: 345-346.

Clarke G.M. 1998: The genetic basis of developmental stability: IV. Individual and population asymmetry parameters. Heredity 80: 553-561

David P., Hingle A., Greig D., Rutherford A., Pomiankowski A. \& Fowler K. 1998: Male sexual ornament size but not 
asymmetry reflects condition in stalk-eyed flies. Proc. R. Soc. London (B) 265: 1-6.

Garcia-Bellido A., Ripoll P. \& Morata G. 1973: Developmental compartmentalisation of the wing disk of Drosophila. Nature (New Biol.) 245: 251-253.

Guerra D., Pezzoli M.C., Giorgi G., Garoia F. \& Cavicchi S. 1997: Developmental constraints in the Drosophila wings. Heredity 79: 564-571.

Hendrickx F., Maelfait J.P. \& Lens L. 2003: Relationship between fluctuating asymmetry and fitness within and between stressed and unstressed populations of the wolf spider Pirata piraticus. J. Evol. Biol. 16: 1270-1279.

Hoffmann A.A. \& Parsons P.A. 1991: Evolutionary Genetics and Environmental Stress. Oxford University Press, Oxford, UK, $296 \mathrm{pp}$.

Imasheva A.G., Loeschcke V., Zhivotovsky L.A. \& Lazebny O.E. 1997: Effects of extreme temperatures on phenotypic variation and developmental stability in Drosophila melanogaster and Drosophila buzzatii. Biol. J. Linn. Soc. 61: $117-126$

James A.C., Azevedo R.B.R. \& Partridge L. 1997: Genetic and environmental responses to temperature of Drosophila melanogaster from a latitudinal cline. Genetics 146: 881-890.

Kark S., Safriel U.N., Tabarroni C. \& Randi E. 2001: Relationship between heterozygosity and asymmetry: a test across the distribution range. Heredity 86: 119-127.

LEARY R.F. \& AllendorF F.W. 1989: Fluctuating asymmetry as an indicator of stress: implications for conservation biology. Trends Ecol. Evol. 4: 214-217.

Lens L., Van Dongen S. \& Matthysen E. 2002: Fluctuating asymmetry as an early warning system in the critically endangered Taita thrush. Cons. Biol. 16: 479-487.

MARKOW T.A. 1995. Evolutionary ecology and developmental instability. Annu. Rev. Entomol. 40: 105-120.

Mpho M., Callaghan A. \& Holloway G.J. 2002: Effects of temperature and genetic stress on life history and fluctuating wing asymmetry in Culex pipiens mosquitoes. Eur. J. Entomol. 99: 405-412.

PALMER A.R. 1994: Fluctuating asymmetry analysis: a primer. In Markow T.A. (ed.): Developmental Instability: Its Origins and Evolutionary Implications. Kluwer Academic, Dordrecht, pp. 335-364.

PAlmer A.R. \& STRobeck C. 1986: Fluctuating asymmetry: measurement, analysis, patterns. Annu. Rev. Ecol. Syst. 17: $391-421$.
Palmer A.R. \& Strobeck C. 2002: Fluctuating asymmetry analyses revisited. In Polak M. (ed.) Developmental Instability: Causes and Consequences. Oxford University Press, New York, pp. 279-319.

Parsons P.A. 1961: Fly size, emergence time and sternopleural chaeta number in Drosophila. Heredity 16: 455-473.

Parsons P.A. 1962: Maternal age and developmental variability. J. Exp. Biol. 39: 251-260.

PARSONS P.A. 1990: Fluctuating asymmetry: an epigenetic measure of stress. Biol. Rev. 65: 131-145.

PARsons P.A. 1992: Fluctuating asymmetry: a biological monitor of environmental and genomic stress. Heredity 68: 361-364.

Pezzoli M.C., Guerra D., Giorgi G., Garoia F. \& Cavicchi S. 1997: Developmental constraints and wing shape variation in natural populations of Drosophila melanogaster. Heredity 79: 572-577.

Pomiankowski A. 1997: Genetic variation in fluctuating asymmetry. J. Evol. Biol. 10: 51-55.

RASMUSON M. 2002: Fluctuating asymmetry indicator of what? Hereditas 136: 177-183.

Roy B.A. \& Stanton M.L. 1999: Asymmetry of wild mustard, Sinapis arvensis (Brassicaceae), in response to severe physiological stresses. J. Evol. Biol. 12: 440-449.

SOKAL R.R. \& RohlF F.J. 1981: Biometry. 2nd ed. Freeman, New York, 859 pp.

Swaddle J.P., Cuthill I.C. \& Witter M.S. 1994: The analysis of fluctuating asymmetry. Anim. Behav. 48: 986-989.

VAn Dongen S. \& Lens L. 2000: The evolutionary potential of developmental instability. J. Evol. Biol. 13: 326-335.

VAN VeLEN L. 1962: A study of fluctuating asymmetry. Evolution 16: 125-142.

VeličKović M. 2004: Chromosomal aberrancy and the level of fluctuating asymmetry in black-striped mouse (Apodemus agrarius): effects of disturbed environment. Hereditas 140: $112-122$.

Völlestad L.A., Hindar K. \& Møller A.P. 1999: A metaanalysis of fluctuating asymmetry in relation to heterozygosity. Heredity 83: 206-218.

Waddington C.H. 1942: Canalization of development and the inheritance of acquired characters. Nature 150: 563-565.

ZaKHAROV V.M. 1992: Population phenogenetics: analysis of developmental stability in natural populations. Acta Zool. Fenn. 191: 7-30.

Received July 20, 2004; revised October 12, 2004; accepted November 26, 2004 